\title{
Amplificación del gen TSPY1 como método de sexaje en bovinos
}

\author{
Amplification of the TSPY1 gene as a sexing method in cattle \\ Diego Alberto Montano Vizcarra', Armando Hung Chaparro ${ }^{1}$ \\ RESUMEN
}

La investigación tuvo como objetivo optimizar un protocolo existente para el sexaje de ganado bovino usando primers específicos para el gen TSPY 1 mediante la técnica de Reacción en Cadena de la Polimerasa (PCR). Para este propósito, muestras de sangre fueron obtenidas de centros de beneficio en la ciudad de Lima. El tamaño de la muestra fue de 60 animales (30 machos y 30 hembras). Así mismo, la técnica fue probada en muestras de ADN de embriones. El ADN extraído de muestras provenientes de animales machos mostró una amplificación del gen TSPY1 mientras que aquel obtenido de animales hembras no mostró dicha amplificación. Similares resultados fueron obtenidos de muestras de ADN obtenidas de embriones.

PALABRAS CLAVE: Gen TSPY1, sexaje, PCR, transferencia embrionaria, bovino.

\section{SUMMARY}

This research was undertaken to optimize a previously described protocol for sexing cattle using the Polymerase Chain Reaction (PCR) molecular technique with specific TSPY1 gene primers. For this purpose, blood samples were obtained from slaughterhouses in the city of Lima. The sample size was 60 animals (30 males and 30 females). Likewise, the technique was tested in DNA samples obtained from embryos. The extracted DNA obtained from male samples showed an amplification of the TSPY1 gen while the one obtained from female samples did not show any amplification. Similar results were obtained from DNA samples obtained from embryos.

KEY WORDS: TSPY1 gen, sexing, PCR, embryo transfer, bovine.

\section{INTRODUCCIÓN}

Los sistemas de producción bovina intensivos buscan obtener altos rendimientos, ya sea en ganado de carne como de leche, en el menor tiempo posible y minimizando costos de producción. En ese aspecto, los temas reproductivos juegan un rol importante para asegurar la progenie según el tipo de producción. Para ello se cuenta con la inseminación artificial usando semen de toros previamente seleccionados de acuerdo a las características productivas deseadas y la transferencia embrionaria que viene siendo utilizada en distintos países de Latinoamérica, la cual involucra el correcto sexaje de los embriones antes de ser transferidos (Almeyda y Díaz, 2006).

El sexaje de las crías brinda muchas oportunidades para el productor porque permite seleccionar a los animales más adecuados para los sistemas de producción que se requieran (Divar, Sharifiyazdi y Kafi, 2012). Una manera práctica y eficiente de realizarlo es mediante la identificación del cromosoma Y que permite reconocer a los machos y diferenciarlos de las muestras que no amplifican dicho cromosoma, las cuales son clasificadas como hembras (Hamilton et al., 2011).

1 Facultad de Medicina Veterinaria y Zootecnia, Universidad Peruana Cayetano Heredia. Lima, Perú. 
Existen técnicas como la hibridación fluorescente in situ (FISH) para la detección del cromosoma Y además de la reacción en cadena de la polimerasa (PCR) la cual es ampliamente utilizada para realizar pruebas de sexaje, paternidad, entre otras (Cenariu et al. 2011). Con esta última, se puede determinar el sexo del ganado bovino al amplificar secuencias del cromosoma y usando primers específicos para cierto gen que posea ese cromosoma. Uno de estos genes es el ZFY (gen Y que codifica la proteina zinc finger), el cual viene siendo utilizado para determinar el sexo en muestras óseas de restos antiguos (Gabbianelli, De Minicis, Valentini y Pariset, 2012) y en camélidos sudamericanos (Montenegro, Maturrano, Wheeler y Rosadio, 2012). Asimismo, el gen Y de la amelogenina (AMELY), que codifica una proteína de matriz extracelular que está involucrada en la biomineralización durante el desarrollo del esmalte dental, es utilizado para determinar el sexo en carcasas de ganado bovino (Zeleny, Bernreuther, Schimmel y Pauwels , 2002) y en rumiantes salvajes (Pajares et al., 2007). También el gen SRY viene siendo utilizado en embriones de ovinos (Calvo, Martínez-Royo, Sánchez y Folch, 2005) y conejos recién nacidos (Vašíček, Vašíčková, Parkányi y Ondruška, 2011). Otro gen denominado TSPY1 (gen Y que codifica una proteína específica testicular), hallado en varias especies de mamíferos incluyendo al humano, caballo y ganado bovino y aparentemente restringido a las células germinales masculinas, viene siendo utilizado en programas de sexaje de embriones en la especie bovina (Carneiro et al., 2011; Hamilton et al., 2012).

En el Perú no se ha difundido el uso de métodos de sexaje molecular mediante la técnica de PCR además de que la transferencia de embriones sexados no es un procedimiento de rutina para el médico veterinario que se dédica al área de animales de producción. En este contexto, el objetivo del estudio fue reproducir y optimizar un protocolo de sexaje mediante el uso de PCR con primers específicos para el gen TSPY1, en muestras sanguíneas de bovinos de la Costa Central del Perú, con la finalidad de adaptar una técnica eficiente y aplicable para las transferencias de embriones sexados en nuestro medio.

\section{MATERIAL Y MÉTODOS}

El estudio recolecto muestras de sangre de 30 bovinos machos y 30 hembras de distintos centros de producción pecuaria en la ciudad de Lima - Perú. Los animales escogidos para el estudio fueron de distintas razas, edades, tipos de alimentación y sistemas de crianza.

Los animales fueron sujetados para facilitar la toma de muestras. La obtención de la misma se realizó mediante punción intravenosa a nivel de la vena yugular y colectadas en tubos de $3 \mathrm{ml}$ con ácido etilendiaminotetraacético (EDTA), debidamente etiquetados con el sexo del animal y un código para su posterior identificación. Las muestras fueron colocadas en un recipiente térmico con hielo gel refrigerante a una temperatura de $4^{\circ} \mathrm{C}$ aproximadamente y fueron transportadas al Laboratorio de Biología Molecular (LBM) de la Facultad de Medicina Veterinaria y Zootecnia (FAVEZ) de la Universidad Peruana Cayetano Heredia (UPCH) donde fueron almacenadas a una temperatura de $-20^{\circ} \mathrm{C}$ hasta su procedimiento.

Así mismo, un embrión de ganado bovino de 8 células fue obtenido (provisto por el Laboratorio de Reproducción de la Universidad Nacional Agraria La Molina) y almacenado en su totalidad junto a las muestras de sangre para su posterior extracción de ADN e identificación de sexo.

La extracción de ADN genómico se realizó empleando el protocolo para la purificación de ADN en sangre y otros fluidos corporales usando el DNA Blood Mini Kit (Qiagen - Sample \& Assay Technologies) tanto para las muestras de sangre como para el embrión. Para ello, primero se agregaron 20 $\mu \mathrm{L}$ de proteinasa $\mathrm{K}$ en un tubo eppendorf de $1.5 \mathrm{ml}$, luego se agregaron $200 \boldsymbol{\mu l}$ de la muestra de sangre. Acto seguido se agregaron $200 \boldsymbol{\mu l}$ de Buffer AL y se homogenizó por 15 segundos. Una vez concluido este paso se incubó la muestra a $56^{\circ} \mathrm{C}$ por 10 minutos y luego a $100^{\circ} \mathrm{C}$ por otros 10 minutos. Luego se agregaron 200 $\mu \mathrm{l}$ de etanol al $100 \%$ y se homogenizó por 15 segundos. Posteriormente se centrifugó brevemente y se agregó a una columna de centrifugación con silica en un tubo de colección de $2 \mathrm{ml}$ y se centrifugó a $8000 \mathrm{rpm}$ por 1 minuto colocándose en un tubo de colección nuevo y descartándose el filtrado. Se agregaron $500 \mu \mathrm{l}$ de Buffer AW1 y se centrifugó a $8000 \mathrm{rpm}$ por 1 minuto eliminando el filtrado obtenido. Se agregaron después $500 \mu \mathrm{l}$ de Buffer AW2 y se centrifugó a la máxima velocidad (13000 rpm) por 3 minutos descartando el filtrado. Se cambió el tubo de colección por un tubo eppendorf y se agregaron $200 \mu 1$ de Buffer de elución $\mathrm{AE}$, se incubó a temperatura ambiente por 5 minutos y se centrifugó a 8000 rpm por 1 minuto. 
Finalmente el ADN obtenido fue congelado a una temperatura de $-20^{\circ} \mathrm{C}$ hasta su procesamiento por PCR. Así mismo, como control del proceso de extracción se inoculó una muestra de ADN extraído de macho con una alícuota de la muestra del ADN embrionario extraído, denominándose embrión inoculado (EI).

La reacción en cadena de la polimerasa (PCR) se empleó para la amplificación del gen TSPY1 y se utilizó el protocolo descrito por Carneiro et al., 2011. Las secuencias de los primers (Life Technologies Corporation), con base en secuencias reportadas en otros estudios (GenBank No. X74028.1, B. taurus TSPY1 gene) (Jakubiczka, Schnieders y Schmidtke, 1993), fueron las siguientes: forward 5'-CCCGCACCTTCCAAGTTGTG-3' y reverse 5'-TGCTCCTCCACCGTCTTCT-3'. La mezcla de reactivos para un volumen final de $50 \mu \mathrm{l}$, usando el PCR Master Mix (2X) (Thermo Scientific), fue la siguiente: $5 \mu \mathrm{l}$ de $10 \mathrm{X}$ Taq Buffer con $\left(\mathrm{NH}_{4}\right)_{2} \mathrm{SO}_{4}$ 1-4 $\mathrm{mM}$ de $\mathrm{MgCl}_{2}, 5 \mu \mathrm{l}$ de dNTPs $(0.2 \mathrm{mM}), 0.1-1.0 \mu \mathrm{M}$ de cada primer (forward y reverse), $1.25 \mathrm{U}$ de ADN Taq Polimerasa y $10 \mathrm{pg}-1 \mu \mathrm{g}$ de ADN extraído.

La secuencia de ADN fue amplificada en un termociclador Veriti 96 (Applied Biosystems) por un primer paso de desnaturalización a $95^{\circ} \mathrm{C}$ por 1 minuto, seguida por 40 ciclos de desnaturalización a $95^{\circ} \mathrm{C}$ por 45 segundos, un proceso de hibridación a $60^{\circ} \mathrm{C}$ por 45 segundos y elongación a $68^{\circ} \mathrm{C}$ por 45 segundos y finalmente una extensión a $10^{\circ} \mathrm{C}$ por 10 minutos.

Los productos resultantes del PCR fueron analizados mediante electroforesis en gel de agarosa al 1,5\% en Buffer Tris, Acetato y EDTA (TAE) $1 \mathrm{X}$ por un tiempo de 40 minutos a 70 voltios con amperaje de 170 amp. El tamaño molecular fue evaluado usando un marcador estándar (GeneRuler DNA - Thermo Scientific), con escalas de 100 a 1000 bp.

La documentación de los resultados de la electroforesis se realizó en un transiluminador de luz UV, siendo considerados como machos aquellos cuyo producto de amplificación era de aproximadamente
328 pares de bases (bp). Así mismo, la ausencia de esta amplificación determinó la condición de hembra para la muestra analizada.

\section{RESULTADOS}

Luego del procedimiento de detección molecular del gen TSPY1 fueron reportados resultados de marcación positiva y negativa para machos y hembras, respectivamente. Además, el embrión resulto ser hembra.

La figura 1 muestra los resultados de 9 machos, 6 hembras, embrión y embrión inoculado. Las muestras de ADN obtenidas de animales machos mostraron la banda positiva (328 bp) en todos los casos (machos 1-9), mientras que las muestras de ADN obtenidas de animales hembras no mostraron una banda (hembras A-F).

En el caso de la muestra de ADN embrionaria, no se obtuvo alguna banda por lo que se determinó como sexo hembra. Para el caso del control de extracción EI se obtuvo una banda y fue clasificado como positivo.

\section{DISCUSIÓN}

El estudio adaptó y optimizó un protocolo publicado (Carneiro et al., 2011) utilizado para detectar el sexo mediante muestras de ADN embrionario, para ser usado en muestras de sangre provenientes de ganado bovino de una manera rápida y específica. Así mismo se detectó el sexo en una muestra de ADN embrionario. Al igual que en reportes anteriores que utilizaron muestras de sangre de camélidos (Montenegro et al., 2012; Arias y Huanca, 2009), ganado bovino (Lemos et al., 2005; Lemos et al., 2011) y rumiantes salvajes (Pajares et al., 2007), los resultados obtenidos fueron los esperados.

Durante el desarrollo del estudio se registró la presencia de bandas inespecíficas por lo que se procedió a incrementar la concentración de $\mathrm{MgCl}_{2}$ de $1.5 \mathrm{mM}$ a $2 \mathrm{mM}$ y disminuir la temperatura de hibridación

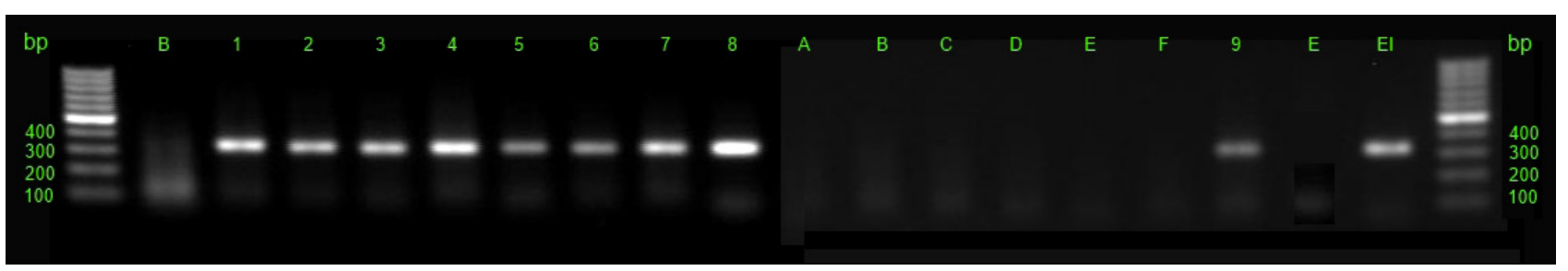

Figura 1. Resultados de la electroforesis en gel de agarosa al 1.5\% para el gen TSPY1. (bp) marcador molecular (escalas de 100 bp); (B) muestra blanco; (1-8) muestras de animales machos; (A-F) muestras de animales hembras; (9) muestra de animal macho; (E) muestra de embrión; (EI) muestra de embrión inoculado con ADN de macho. 
en $2^{\circ} \mathrm{C}$, es decir de $60^{\circ} \mathrm{C}$ a $58^{\circ} \mathrm{C}$, logrando eliminar las reacciones inespecíficas (Thermo Scientific, PCR Troubleshooting).

Las muestras de sangre son de elección en el caso del ganado bovino. Esto pudo ser replicado durante el proceso de toma de muestras en el estudio y corroborado al analizar los resultados. Por otro lado, la detección del sexo a partir de una muestra de ADN mediante PCR puede ser realizada usando primers específicos de distintos genes como el SRY, TSPY1, y otros. Dado que el gen TSPY1 es multicopia, es decir, presenta varias copias en bajas concentraciones de ADN, resulta más útil y eficiente como marcador masculino a diferencia de otros genes como el SRY que es de 1 sola copia (Lemos et al., 2005).

Según reportes anteriores (Park etal., 2001; Carneiro et al., 2011), escoger embriones morfológicamente superiores y con un mayor número de blastómeros genera porcentajes de eficiencia más altos al momento de realizar el sexaje molecular. El estudio se utilizó un embrión constituido por 8 células o blastómeros por lo que se recomienda el uso de embriones en estadios más avanzados para estudios futuros en los que se desee probar la eficacia del procedimiento.

Así mismo, el uso de esta técnica molecular puede colaborar como herramienta de investigación en la detección de ADN fetal en la circulación materna (Lemos et al, 2011). Se sabe que la placenta de los bovinos es mesocorial, es decir, el corion entra en el endometrio sin llegar a tocar los vasos sanguíneos de la madre por lo que resulta difícil dilucidar el mecanismo por el cual este pasaje sucede. De todos modos, esta evidencia sola resulta útil para detectar el género fetal e invita a la exploración por otros modelos como la investigación farmacológica en busca de establecer nuevas vías para el transporte placentario de drogas.

De misma forma, la detección del cromosoma Y mediante PCR resulta beneficiosa en los estudios de quimerismo en ganado bovino. En un trabajo anterior se pudo diagnosticar de una manera rápida y efectiva los varios tipos de síndrome de freemartin en bovinos mediante la técnica molecular de PCR usando muestras de sangre (Fujishiro, Kawakura, Miyake y Kaneda, 1995).

El uso del semen previamente sexado provee un panorama a futuro con ventajas económicas para la producción de ganado bovino si la tecnología mejora y los costos se reducen. El proceso de sexaje de semen tiene una eficacia del $90 \%$ aproximadamente cuando todas las demás constantes (manejo sanitario, alimentación, etc.) se encuentran excelentes, además que el conteo del esperma debe ser realizado de manera visual por lo que resulta un proceso lento como costoso, razón que se ve reflejada en el precio final del mismo (Seidel, 2003; Carneiro et al., 2011). En contraste, el uso de PCR para el sexaje de embriones usando secuencias de TSPY1 puede ofrecer mejores índices y un mayor número de embriones del sexo deseado.

Los resultados del estudio representa el primer reporte en el Perú en el que se usó el gen TSPY1 para el sexaje de ganado bovino adulto y embriones usando PCR. Este proceso de optimización puede servir para promover el uso del PCR como técnica de detección del sexo en embriones para su posterior aplicación en la práctica de transferencia de embriones.

\section{CONCLUSIONES}

Se comprobó la efectividad del PCR con el uso de primers específicos para el gen TSPY1, como marcador de sexo, para el sexaje de bovinos mediante la adaptación de un protocolo molecular y su potencial uso con muestras clínicas provenientes de ganado bovino y de embriones.

\section{Correspondencia}

\section{Diego Montano Vizcarra \\ Correo electrónico: diego.montano@upch.pe}

\section{REFERENCIAS BIBLIOGRAFICAS}

1. Almeyda, J., \& Díaz, R. (2006). Primeros resultados del mejoramiento genético de vacunos en las zonas alto andinas utilizando la transferencia de embriones de razas puras en el útero de vacas criollas. Rev Agro Enfoque, 21, 149.

2. Arias, C., \& Huanca, L. (2009). Un método para el sexaje por ADN de alpaca amplificando el gen SRY mediante PCR ${ }^{1}$. Revista de Investigaciones Veterinarias del Perú, 20(2), 203-207.

3. Calvo, J. H., Martínez-Royo, A., Sánchez, P., \& Folch, J. (2005). Sex determination in ovine embryos by PCR: production of genetic improvement rams for the sheep breeding improvement programme of UPRA [Producer's Association of Rasa Aragonesa sheep breed]-Oviaragón [2005]. Roma: Instituto Nacional de Investigación y Tecnología Agraria y Alimentaria

4. Carneiro, M. C., Takeuchi, P. L., Araújo, A., Lôbo, R. B., Elias, F. P., Vila, R. A., ... \& Ramos, E. S. 
(2011). Sexing single bovine blastomeres using TSPY gene amplification. Genet. Mol. Res, 10(4), 39373941.

5. Cenariu, M. I. H. A. I., Groza, I., Pall, E., Bogdan, L., Morar, I., \& Pop, R. (2011). Sexing of bovine embryos using polymerase chain reaction (PCR) and fluorescent in situ hybridization (FISH). Romanian Biotechnological Letters, 16(2), 6056-6061.

6. Divar, M. R., Sharifiyazdi, H., \& Kafi, M. (2012). Application of polymerase chain reaction for fetal gender determination using cervical mucous secretions in the cow. Veterinary research communications, 36(4), 215-220.

7. Fujishiro, A., Kawakura, K., Miyake, Y. I., \& Kaneda, Y. (1995). A fast, convenient diagnosis of the bovine freemartin syndrome using polymerase chain reaction. Theriogenology, 43(5), 883-891.

8. Gabbianelli, F., De Minicis, E., Valentini, A., \& Pariset, L. (2012). A simple and robust method for sexing ancient bovine bones. Open Forensic Science Journal, 5, 9-12.

9. Hamilton, C. K., Combe, A., Caudle, J., Ashkar, F. A., Macaulay, A. D., Blondin, P., \& King, W. A. (2012). A novel approach to sexing bovine blastocysts using male-specific gene expression. Theriogenology, 77(8), 1587-1596.

10. Jakubiczka, S., Schnieders, F., \& Schmidtke, J. (1993). A bovine homologue of the human TSPY gene. Genomics, 17(3), 732-735.

11. Lemos, D. C., Rios, Á. F. L., Caetano, L. C., Lôbo, R. B., Vila, R. A., Martelli, L., ... \& Ramos, E. S. (2005). Use of the TSPY gene for sexing cattle. Genetics and Molecular Biology, 28(1), 117119.
12. Lemos, D. C., Takeuchi, P. L., Rios, Á. F., Araujo, A., Lemos, H. C., \& Ramos, E. S. (2011). Bovine fetal DNA in the maternal circulation: applications and implications. Placenta, 32(11), 912-913.

13. Montenegro, V., Maturrano, H., Wheeler, J. C., \& Rosadio, R. (2012). Determinación del sexo mediante la técnica de reacción en cadena de la polimerasa en camélidos sudamericanos. Revista de Investigaciones Veterinarias del Perú, 23(3), 377-387.

14. Park, J. H., Lee, J. H., Choi, K. M., Joung, S. Y., Kim, J. Y., Chung, G. M., ... \& Im, K. S. (2001). Rapid sexing of preimplantation bovine embryo using consecutive and multiplex polymerase chain reaction (PCR) with biopsied single blastomere. Theriogenology, 55(9), 1843-1853.

15. Pajares, G., Álvarez, I., Fernández, I., Pérez-Pardal, L., Goyache, F. \& Royo, L. (2007). A sexing protocol for wild ruminants based on PCR amplification of amelogenin genes AMELX and AMELY. Archives Animal Breeding, 50(5), 442-446.

16. Seidel, G. E. (2003). Economics of selecting for sex: the most important genetic trait. Theriogenology, 59(2), 585-598.

17. Vašíček, D., Vašíčková, K., Parkányi, V., \& Ondruška, L. (2011). Noninvasive PCR sexing of neonatal rabbits selected for islet cell culture. Slovak J Anim Sci, 44 (2), 43-47

18. Zeleny, R., Bernreuther, A., Schimmel, H., \& Pauwels, J. (2002). Evaluation of PCR-based beef sexing methods. Journal of agricultural and food chemistry, 50(15), 4169-4175. 